\title{
A experiência sociocultural de universitários da África Lusófona no Brasil: entremeando histórias
}

Carlos Subuhana *

Resumo: O objeto de estudo deste trabalho é a presença de estudantes da África Lusófona em São Paulo, Brasil, com a proposta de investigar uma experiência de imigração temporária. Os dados e as evidências coletados para a elaboração do trabalho relacionam-se a: i) projetos de vida e a escolha do Brasil; ii) identidade e sistemas classificatórios; iii) sociabilidade e redes sociais; e, por último, iv) a expectativa do retorno, ou seja, a forma como esses acadêmicos pensam aplicar os conhecimentos adquiridos no Brasil à realidade dos países de origem. Este material foi coletado através de entrevistas, por meio de questôes abertas e fechadas. Este grupo forma uma rede de relações ampliada, a qual acolhe também indivíduos de outras nacionalidades, possibilitando não apenas a vivência de contatos face a face, como também a interação através de redes virtuais. Cabe destacar, ainda, que a expectativa do retorno aos países de origem se faz presente entre os interlocutores.

Palavras-chave: Brasil/África; relações internacionais; relaçōes raciais; sociabilidade.

The sociocultural experience of Portuguese-speaking African university students in Brazil: weaving stories together

Abstract: The aim of this research is the presence of Portuguese-speaking African students in São Paulo, Brazil, focusing on their experience of temporary immigration. The data and instances collected for this research refer to: i) life projects and the choice of Brazil; ii) identity and classifying systems; iii) sociability and social networks and, finally, iv) the expectation of returning home or, in other words, how these students think of applying the newly-acquired knowledge in the reality of their home countries. This material has been gathered by means of interviews, with the use of open and closed questions. This group of students constitutes an amplified network of relationships receiving also individuals of other nationalities and enabling both face-to-face contacts and virtual interaction. It is interesting to emphasize that the expectation of returning home is always present among interlocutors.

Key words: Brazil/Africa; international relations; racial relations; sociability.

A história de minha trajetória pessoal até chegar ao Brasil como estudante universitário revela caminhos comuns aos de outros estudantes africanos de

* Centro de Estudos Africanos da Universidade de São Paulo (CEA/USP), São Paulo, Brasil. subuhana@hotmail.com 
língua portuguesa que para aqui migram em busca de formação intelectual e universitária. Contudo, para falar desses universos entrelaçados, falo antes de minha origem e de minha unidade uterina, posto que elas expõem os caminhos de constituição da cidadania em Moçambique, ontem e hoje, e dizem, também, da busca de diversos povos africanos por sua autonomia e independência, em particular, via campo educacional.

O ponto de partida desta história é a memória oral de minha avó materna, que me revelou a trajetória da nossa sublinhagem $(\text { erukulu })^{1}$, desde a origem até as migrações que ocorreram conosco por vários motivos, motivos esses que fazem parte da história de Moçambique.

Foi em Rutanba (Tanzânia) que passei a maior parte de minha infância. O meu círculo de amizades era composto por refugiados e filhos de refugiados provenientes de várias regiōes e de vários grupos étnicos e lingüísticos de Moçambique, bem como de tanzanianos.

Lá vivíamos como refugiados moçambicanos. Era assim que nos percebíamos e éramos identificados pelos naturais ${ }^{2}$. Cedo começou a surgir entre nós o espírito nacionalista. Os nossos pais nos ensinavam que éramos moçambicanos, estávamos na Tanzânia como refugiados ${ }^{3}$ e teríamos que voltar assim que o nosso país se tornasse independente. Portanto,

Não é por acaso que escolho fazer da minha história de vida um objeto de estudo. Parti do pressuposto de que não se nasce cidadão, torna-se cidadão. A cidadania é algo socialmente construído e a identidade particular faz parte do universo da cidadania. Nasci numa época em que Moçambique atravessava uma fase delicada (princípios da década de 1970), porém decisiva. Uma época em que os moçambicanos começavam a ter em mente que, para além das obrigações familiares, de linhagem e de "tribo", existia algo mais complexo que lhes pertencia e que estava em mãos alheias, ou seja, com os colonizadores. Foi numa época em que os colonizados - basicamente os menos alfabetizados - começavam a perceber que a luta armada engendrada pela Frelimo (Frente de Libertação de Moçambique) tinha certo sentido. Os moçambicanos começaram a perceber que era preciso reforçar a união, deixar de lado os conflitos anteriores, expulsar os colonizadores e tentar edificar uma nação no interi-

1. Erukulu (palavra de língua macua): ventre, unidade uterina, sublinhagem.

2. Os nossos amigos tanzanianos denominavam-nos Wa-Kimbisi, uma palavra da língua Swahili que quer dizer refugiados.

3. A Tanzânia não só acolheu os refugiados moçambicanos, mas também foi a base principal de apoio logístico da luta empreendida pela Frente de Libertação de Moçambique (Frelimo), desde o início (1962). 
or das fronteiras que seriam herdadas desse colonizador ${ }^{4}$. Não sei se conseguimos construir uma nação, mas ao menos conseguimos entrar independentes no concerto do mundo fora da colonização e tivemos flexibilidade para nos adaptarmos razoavelmente ao mapa herdado do colonizador, mesmo não tendo nada a ver com realidades demográficas e étnicas ${ }^{5}$. (Subuhana, 2006, p. 1-2)

É nesse sentido que Moçambique, país independente agora, busca reforçar o diálogo social e político entre campo e cidade, vale dizer, entre "tradição" e "modernidade". "Nesse âmbito assiste-se a um esforço de busca de reconciliação das tradições culturais moçambicanas com políticas sociais e econômicas mais amplas." (Subuhana, 2006, p. 1). Parece ser este um caminho comum para o caso das novas naçôes emergentes em África, nomeadamente, na África de língua portuguesa.

Assim, minha origem inscrita num universo rural moçambicano resultou na convivência com diversidades culturais e étnicas e trouxe implicaçôes para a minha história/trajetória de vida. Por outro lado, ter vivido a maior parte da infância fora de Moçambique, na Tanzânia, ampliou a perspectiva dessa convivência e tornou-me um migrante potencial, fato que também se faz contingente nos demais países dos Palop ${ }^{6}$.

É pela segunda vez que moro no exterior: num primeiro momento como filho de refugiados moçambicanos, durante a guerra de libertação nacional (na Tanzânia), e depois como estudante universitário no Brasil. A minha experiência tem pontos em comum com as experiências dos meus compatriotas e dos demais estudantes estrangeiros, em especial dos estudantes africanos que estudam no Brasil e com os quais convivo. Faço parte dessas relaçôes. Eu também busco e encontro formas de sobrevivência no Brasil, onde construí e construo meus projetos presentes e futuros e troco experiências com as pessoas que me são próximas em termos de convívio, de cultura.

4. "Na nossa unidade há gente de todas as regiões; eu estou com ajauas [os yao], macondes e gente da Zambézia. Creio que isto é bom, antigamente não nos julgávamos uma só nação; a Frelimo mostrou-nos que somos um só povo. Unimo-nos para destruir o colonialismo e imperialismo português" (Mondlane, 1975, p. 164).

5. As fronteiras atuais, de Moçambique, foram estabelecidas em I89I.

6. Palop é o acrônimo de Países Africanos de Língua Oficial Portuguesa. Ou seja, as antigas colônias de Portugal em África, possuindo cada um deles diferentes características geográficas, econômicas e demográficas. Nestes países — Angola, Moçambique, Cabo Verde, Guiné Bissau e São Tomé e Príncipe - a língua portuguesa é o elemento interno de ligação entre as respectivas populações e de projeção no exterior. 


\section{A experiência escolar e universitária}

Num certo dia decidi ir à escola, sem o conhecimento dos meus pais. Era no ano de 1977. Não tinha atingido a idade escolar exigida na época, que era de 7 anos. Tinha apenas cinco 5 anos e meus pais esperavam que eu crescesse mais um pouco, para depois me matricularem. Mesmo assim, eles acabaram consentindo a minha decisão. Depois confessei a eles que a falta de amigos, durante o horário escolar, me incomodava, já que quase todos os meninos do meu círculo de amizade estudavam e eu sentia falta das nossas brincadeiras e da companhia dos garotos. Chegando à escola, o professor Martins recebeu-me e ganhei dele um caderno e um lápis. Naquela ocasião estava se dando o ponto de partida da minha trajetória intelectual na Escola Primária de M'Sawize, em Mavago (Niassa), já em Moçambique.

O nosso dia-a-dia na escola era agradável. Para além das aulas normais, passávamos horas na escola participando de várias atividades culturais. Aprendíamos a dançar, a cantar e a recitar poesias em público, principalmente em dias festivos como o 25 de Junho, 25 de Setembro e em outras datas históricas ${ }^{7}$.

No projeto do governo, na época, as escolas deviam ser "verdadeiros centros [de] divulgação da cultura nacional e do conhecimento político, técnico e científico" (Machel, 1983, p.17); nelas não devia haver lugar para a discriminação social, racial ou com base do sexo (gênero). A difusão do conhecimento devia ter como fim "a mobilização da natureza e do potencial para o desenvolvimento e progresso" (Machel, 1983, p.17). Para isso impunha-se a "democratização dos meios de ensino", os alunos e os professores deviam participar com responsabilidade no processo de criação de uma escola de tipo novo, que valorizasse devidamente o trabalho manual como "uma das fontes do conhecimento" (Machel, 1983, p.17). Professores e alunos, segundo o autor, deviam aprender uns com os outros, num clima de confiança, de relaçôes harmoniosas e de camaradagem em que fosse possível libertar a iniciativa de cada um, valorizando os talentos de todos.

Mesmo sendo um dos beneficiados pela revolução - pois tive acesso à educação primária e secundária e, em seguida, à formação universitária, precisamente por causa da Frente para a Libertação de Moçambique (Frelimo) -, a minha experiência prova que a relação entre professores e alunos não era harmoniosa. O que reinava nas escolas era, basicamente, o que prefiro denominar de cultura do silêncio.

7. Na época, um dos desafios do governo revolucionário da Frente para a Libertação de Moçambique (Frelimo) era a "assimilação nacional de todas as manifestações culturais regionais e étnicas que deveriam ser enfocadas sob [a] óptica da linha político-ideológica de classe, ancorada no materialismo histórico-dialético" (Borges, 2001, p.234-235). 
O silêncio e a disciplina autoritária em sala de aula eram tão perturbadores, quando se pensa na interação e no diálogo necessários na relação ensino/aprendizado! A impressão era a de que não havia espaço para a criatividade, para o questionamento e para a inquieta e saudável curiosidade infantil. Os professores não valorizavam os nossos talentos.

Esse silêncio e essa absoluta ordem, que de tão rígida incomodava, guardavam também outra face. No silêncio, na ordem, na repetição e na cópia, absorvíamos tudo o que nos era permitido. E daí advém o que chamo de cultura do não-desperdício, que não se restringe ao seu aspecto material. No silêncio do ambiente das aulas, o nosso envolvimento e a nossa atenção eram tais que acabávamos absorvendo os conteúdos, não somente por meio das palavras e leituras, mas também por meio de gestos, olhares, comentários, comparações, exemplos, tudo. Ali, nada escapava e nada se perdia.

Nas férias escolares de 1981 minha avó materna decidiu mandar meninos de sua sublinhagem alargada para o jando (rituais de circuncisão), uma cerimônia de iniciação longa, complicada, com rituais compostos de símbolos, magia e tabus. Ela tomou essa decisão porque muitos meninos de nossa sublinhagem alargada estavam terminando a quarta classe (série) e teriam que deixar M'sawize para prosseguir os estudos em diversas escolas, que por sinal ficavam em locais distantes, e ela tinha a máxima certeza de que os ensinamentos ministrados na ndagala (acampamento) seriam importantes para suas vidas. $\mathrm{Eu}$, meu irmão Muemedi ${ }^{8}$ e outros parentes fomos os beneficiados por essa decisão. Chegando à ndagala, juntamo-nos com outros neófitos vindos de outras famílias, compondo um total de 25. Quase todos eram meus colegas de escola. Durante os 30 dias em que residimos na ndagala o convívio foi tão intenso que a nossa amizade se mantém firme até hoje.

Mesmo sendo alunos bem aplicados na escola, eu, meus colegas e amigos, sentíamos a necessidade de passar pelos rituais de circuncisão - jando -, parte da tradição. No nosso círculo de amizade ser circuncidado era sinônimo de mais respeito, mais facilidade em quase tudo, inclusive a facilidade para conquistar namoradas. Quem não passasse por essa experiência, mesmo tendo um nível escolar mais elevado em relação aos demais amigos, sentia-se inferiorizado e era menos respeitado. Para nós, a circuncisão não era simplesmente um ritual de passagem. Fazia parte da construção da nossa masculinidade?

8. Hoje professor e diretor de uma escola do ensino básico no Niassa.

9. Vale assinalar que o jando foi uma das práticas culturais que resistiu às proibições do governo central, cuja política de construção da nação moçambicana, através da Frelimo, propunha uma nação una e moderna. Mesmo assim, quase todos os pais e parentes de várias origens étnicas e lingüísticas mandavam seus filhos a esses ritos, às escondidas, desafiando assim o projeto da Frelimo. 
Deixei de morar na aldeia comunal de M'sawize em fevereiro de 1986, depois de ter terminado a sexta classe do Antigo Sistema de Educação (ASE), indo prosseguir os estudos na cidade de Lichinga. Era a primeira vez que morava longe dos meus pais e parentes, mas acabei me conformando. Decidi (escolhi) fazer da academia uma forma de vida, um estilo de vida. Assim, fiz a $7^{\text {a }}$, $8^{a}$ e $9^{a}$ classes (ASE) na escola secundária Eduardo Mondlane e na escola secundária Paulo Samuel Kankhomba.

Ao terminar a $9^{\text {a }}$ classe, em 1989, fui selecionado para prosseguir meus estudos na escola pré-universitária $1^{\circ}$ de Maio, em Nampula, onde fiz a $10^{a}$ e a $11^{a}$ classes (ASE). Foi na cidade de Nampula que tive a oportunidade de prestar o concurso para a obtenção da bolsa de estudos para prosseguir os estudos em Ciências Sociais na Universidade Federal do Rio de Janeiro, no Brasi ${ }^{10}$.

Depois da nossa chegada ao Brasil, em 1994, tive a oportunidade de fazer parte do Núcleo de Etnologia Indígena (NEI) e do Programa de Estudos sobre África Austral (PEAA), que compõem o Laboratório de Pesquisa Social (LPS) do Instituto de Filosofia e Ciências Sociais (IFCS) da Universidade Federal do Rio de Janeiro (UFRJ).

Assim, ao longo do curso de graduação, pude pegar o gosto pela pesquisa. Eu e os demais compatriotas aproveitamos nossas férias anuais, em Moçambique, para levantar dados que pudéssemos compartilhar com nossos orientadores, professores e colegas. Foi nesse ambiente acadêmico que conhecemos os professores: José Ricardo Ramalho, Marco Antonio Gonçalves, Mar-

10. "Nos últimos anos da guerra [civil], começou a crescer em Moçambique o consenso, entre os da intelectualidade, de que a luta da Frelimo contra a heterogeneidade lingüística e cultural tinha, de fato, fortalecido a Renamo. Com isso começaram a surgir interpretações que fugiam da ortodoxia marxista. Surgiu a vontade de fortalecer as Ciências Sociais em Moçambique. Mas havia pouca gente formada em Antropologia, Sociologia e Ciência Política, e ainda não havia uma faculdade de Ciências Sociais na Universidade Eduardo Mondlane. A Fundação Ford e o Ministério da Educação responderam a este desejo financiando um programa, através do qual 20 jovens moçambicanos teriam a oportunidade de cursar o bacharelato em Ciências Sociais no Instituto de Filosofia e Ciências Sociais da Universidade Federal do Rio de Janeiro. Em 1989, os primeiros bolsistas foram escolhidos em concurso aberto nas cinco escolas pré-universitárias de Moçambique [nas províncias de Gaza, Maputo, Nampula, Sofala e Zambézia], começando os seus estudos em 1990. De 199I a 1993 vieram para o Brasil mais de cinco bolsistas por ano, completando o total de 20 [, a saber: Cristiano Matsinhe, João Carlos Colaço, José Jaime Macuane, Manuel Macia e Fátima Mussa - primeira turma; Adriano Maurício, Dulce João, Maria Teresa Rufai Mendes, Sérgio Baleira e Sônia Nhantumbo - segunda turma; Graciano Langa, Joaquim Miguel Castigo Fumo, Margarida do Rosário, Máximo Bonifácio e Pedro Inglês - terceira turma; e Alcinda Salvado, André Alfredo Zaqueu Wandela, Carlos Subuhana, Ludovico José Chuquela e Sérgio Nipaquela - quarta turma]. Estudando com dedicação e seriedade ímpares, todos estes alunos se formaram em quatro anos ou até menos. Treze voltaram imediatamente para Moçambique, enquanto outros sete prestaram concurso para cursos de pós-graduação no Rio de Janeiro, obtendo o grau de mestre. Destes, três seguiram o doutorado" (Fry, 200 I, p. I6- I7).

Pro-Posiçōes, Campinas, v. 20, n. 1 (58), p. 103-126, jan./abr. 2009 
co Antonio da Silva Mello e Peter Fry, que foram indispensáveis na nossa formação acadêmica.

Terminada a graduação, os quatro colegas que fizeram parte da última turma do "Projeto Moçambique" retornaram imediatamente para Moçambique, enquanto eu prestei um concurso de mestrado, em 1998, no Programa de PósPraduação em Sociologia e Antropologia (PPGSA) do IFCS da UFRJ, obtendo o grau de mestre em Sociologia (com concentração em Antropologia), em 2001. Em março de 2001 ingressei no curso de doutoramento em Serviço Social da Escola de Serviço Social - UFRJ —, através de um processo seletivo, tendo conquistado o título de doutor em Serviço Social em maio de 2005.

\section{"Quem não viaja vai casar com a[o] própria[o] irmã[o]" (ditado bantu)}

Em 2007 ingressei no Programa de Pós-Doutorado em Antropologia da Universidade de São Paulo - USP. Tinha por projeto dar continuidade aos meus estudos realizados no doutorado da UFRJ ${ }^{11}$, agora buscando compreender a experiência de estudantes provenientes de Países Africanos de Língua Oficial Portuguesa (Palop $)^{12}$ em universidades e instituições de formação profissional - públicas e particulares - de São Paulo. No Rio de Janeiro, o trabalho de doutorado ateve-se a estudantes de nacionalidade moçambicana. Tratou-se, portanto, de um segmento nacional dentre as nacionalidades que compóem o conjunto de estudantes africanos naquele Estado brasileiro. No caso do estudo de São Paulo, considerou-se o conjunto de nacionalidades componentes dos Palop - Angola, Cabo Verde, Guiné Bissau, Moçambique e São Tomé e Príncipe - , sendo esse universo uma ampliação da questão tratada no Rio de Janeiro, fato que considerou, ainda, a especificidade de outra região. Em segundo lugar, a ampliação do universo correspondeu, também, a uma abordagem mais complexa, não só pela questão das várias nacionalidades, mas também pela diversidade de origens sociais e étnicas desse universo, a quais, com suas histórias singulares, revelam novos ângulos das questôes já postas pelo primeiro estudo. Um terceiro ponto foi que, nesse novo contexto, havia a expectativa de que o emergir de dados novos e significativos pudesse permitir descobertas significativas para pensar os deslocamentos com finalidade de estudo entre África e Brasil e, ainda, proporcionar uma reflexão mais teórica do sentido

11. Título da pesquisa: O Estudante convênio: a experiência sociocultural de universitários da África Lusófona em São Paulo - Brasil. Supervisor: Prof. Dr. Kabengele Munanga, USP. Período: 20062007.

12. Palop é o acrônimo de Países Africanos de Língua Oficial Portuguesa, ou seja, as antigas colônias de Portugal em África, possuindo cada um deles diferentes características geográficas, econômicas e demográficas. Nesses países a língua portuguesa é o elemento interno de ligação entre as respectivas populações e de projeção no exterior. 
desses fluxos e da proposta inicial, qual seja, a construção da identidade e da cidadania.

Vale comunicar que aqui a proposta foi investigar a experiência social e cultural dessa população - comumente portadora do "visto temporário tipo IV" - que está no Estado de São Paulo principalmente fazendo seus estudos universitários, em nível de graduação ou pós-graduação. Restringir o universo de pesquisa teve por finalidade afirmar que as questões que esses estudantes se colocam não são apenas inerentes a seu grupo; ao contrário, elas também se fazem presentes em outros universos sociais, basicamente em outras situações de dinâmicas populacionais e/ou migratórias, como as estudadas por Leandro (2004), Petrus (2001), Sayad (1998), Subuhana (2005), entre outros.

Segundo os ensinamentos de Elias e Scotson (2000), o uso de uma pequena unidade social como foco de investigação de problemas igualmente encontráveis numa grande variedade de unidades sociais, maiores e mais diferenciadas, possibilita a exploração desses problemas com uma minúcia considerável - "microscopicamente, por assim dizer". Esses teóricos afirmam que "se pode construir um modelo explicativo, em pequena escala, da configuração que se acredita ser universal [...]” (Elias; Scotson, 2000, p.20).

É difícil fornecer dados quantitativos que caracterizem essa população. Existe imensa dificuldade de obter dados efetivos desse contingente estudantil, como mostram inúmeros trabalhos feitos com o tema, dentre os quais cito o de Edilma Desidério (2006) que, em sendo funcionária do IBGE, fala da incerteza dos dados nessa fonte e em outras, como a Polícia Federal. Lembro ainda que os sistemas de registros das universidades brasileiras quanto à origem desses estudantes são irregulares e falhos, o que impossibilita saber quantos são de fato. Os dados de que disponho apontam para a faixa etária dessa população, que varia de 18 a 44 anos, havendo um ligeiro equilíbrio entre o número de homens e mulheres.

Poucas são as famílias constituídas de marido, mulher e filhos. Durante as entrevistas identifiquei quatro casais, a saber: um casal de cabo-verdianos, um outro de moçambicanos, um casal constituído por uma cabo-verdiana e um russo, um outro formado por uma guineense e um brasileiro e um casal constituído por um moçambicano e uma brasileira.

Os estudos desses universitários são financiados por seus próprios pais e parentes ${ }^{13}$, por organizações não-governamentais $(\mathrm{ONGs})^{14}$, pelos governos

\footnotetext{
13. Pais e parentes têm como obrigação assinar um termo de compromisso no qual afirmam estar em condições de custear os estudos de seu filho e/ou parente, sendo que o valor mínimo exigido é de 300/500\$00 (quinhentos dólares americanos) mensais.

14. The Ford Foundation, Banco Mundial, Fnuap, entre outras.
} 
dos países de origem (via ministérios), pelo governo brasileiro (Capes/MEC, CNPq), bem como por empréstimos bancários.

Em razão de serem contingentes relativamente pequenos e de difícil acesso, mesmo para outro africano, quantificá-los pode conduzir a resultados pouco expressivos. Assim, de modo muito geral e somente com relação aos efetivamente entrevistados, pode-se afirmar que em termos de origens sociais, os pais e parentes desses estudantes são, em sua maioria, membros de altos escalóes do governo (como ministros e governadores, por exemplo), empresários, funcionários dos setores público, privado e de ONGs, ou seja, pertencem a famílias de alto status socioeconômico e político. Os poucos filhos de camponeses ou de funcionários que auferem salários baixos conseguem entrar no Brasil para prosseguir com seus estudos universitários através de bolsas de estudos, basicamente em nível de pós-graduação (mestrado e doutoramento). Muitos são provenientes das capitais dos países de origem - Bissau, Luanda, Maputo, Praia, São Tomé - e de cidades como Beira, Príncipe, Santo Antão e São Vicente.

Essa população se identifica a partir de classificações distintas que se referem a distinções étnico-raciais e lingüísticas que podem ou não se cruzar como negros, mestiços, indianos, mulatos e brancos; fulas, macuas, umbundus e rongas; são bilíngües e/ou multilíngües, ou seja, falam português, emakhwa, ciyao, bitonga, crioulo, kikongo, inglês e francês, entre outras línguas.

As Instituições de Ensino Superior (IES) nos cinco países estão em processo de grande expansão e também de inovação. Mesmo assim, é fato que um número ínfimo de alunos alcança o nível universitário que, se cresceu nos últimos anos com a criação de instituiçôes privadas de ensino que se estabeleceram também fora das capitais (especialmente nas cidades de Corimba/Angola, Mindelo/Cabo Verde e Nampula/Moçambique), ainda atendem diminuto número de cidadãos. Os estudantes universitários representam um segmento microscópico em relação ao total da população, não atingindo $1 \%$. O perfil comum que caracteriza as instituiçôes de ensino superior e pesquisa dos Palop apresenta as seguintes características: i) dificuldade de acesso a recursos; e ii) elevada dependência de doaçôes externas para o ensino e, particularmente, para a pesquisa. Hoje, os cinco países contam com 55 IES que estão assim distribuídas: Angola, 16 ${ }^{15}$; Cabo Verde, 8; Guiné Bissau, 3; Moçambique, 256; e São Tomé e Príncipe, 3.

Já que o número de potenciais candidatos ao ensino superior não pára de crescer e as universidades nacionais - sobretudo as universidades públicas -

15. Até 1999 tinha uma Universidade, a Universidade Agostinho Neto, fundada em 1962.

16. A Universidade Eduardo Mondlane, a maior e a mais antiga, fundada em 1962, hoje conta com 12 Faculdades. 
não conseguem absorver essa demanda, hoje a opção de alguns pais e familiares tem sido enviar seus filhos para realizarem seus estudos universitários no exterior, em especial em Portugal, África do Sul e Brasil. Ao que consta, a primeira geração de estudantes dos Palop a emigrar para o exterior a fim de prosseguir com seus estudos universitários ocorreu nos meados da década de 1950 através das missões (igrejas) protestantes — num primeiro momento, para África do Sul e para outras colônias inglesas; e depois para Portugal, França, Suíça, RDA, EUA e Inglaterra, entre outros países. Dessa primeira geração, que manteve contato com a esquerda européia através do Partido Comunista Francês e com os ideais liberais florescentes nos EUA, surgiram as principais lideranças ${ }^{17}$ que conduziram os processos de luta interna em nome da independência de seus países.

\section{Migrar com finalidade de estudo}

A principal questão teórica que se coloca é a da e/migração (Sayad, 1998); no caso presente, e/imigração temporária. Prefiro usar usar o termo "imigração temporária" por acreditar que o conceito "imigração" strictu sensu seria definitivo demais, uma vez que esses estudantes entram no Brasil com o "Visto Temporário IV”, que pode ser renovado e prorrogado anualmente, bem como transformado em Visto Permanente. Migrações temporárias seriam, de acordo com Maria Beatriz Rocha-Trindade (1995), os movimentos migratórios a que correspondem estadias a priori limitadas no tempo, e uma das situaçōes singulares seria a dos estudantes que, em países estrangeiros, visam obter determinadas qualificaçōes, sobretudo em programas de ensino superior graduado e pósgraduado de longa duração (Muus, 1995, p.170).

Outros temas, como sociabilidade e redes sociais, a idéia de projeto e trajetória, são abordados a partir da questão principal. A base do meu trabalho trabalho consiste em investigar e compreender como esses estudantes experimentam a vivência de sair de seus países; o porquê dessa iniciativa; o que acontece quando chegam ao Brasil; o que vêm a se tornar quando chegam aqui; como constroem suas próprias identidades e auto-imagem; como se relacionam nesse novo contexto; e, depois, como voltam, o que os faz voltar, de que maneira voltam e quem volta.

O material aqui analisado foi coletado através de entrevistas (com questões fechadas e abertas) com estudantes da África Lusófona que estão fazendo cursos

17. Os nomes das lideranças mais conhecidas e famosas são: Agostinho Neto (Angola), Amílcar Cabral (Cabo Verde e Guiné Bissau), Eduardo Mondlane e Marcelino dos Santos (Moçambique), Miguel Trovoada (São Tomé e Príncipe), entre outros. 
em universidades públicas ${ }^{18}$ e privadas $^{19}$ de São Paulo. A escolha dos entrevistados foi aleatória. As entrevistas ocorreram nas casas dos interlocutores ou em suas universidades, em minha casa, em festas ou no Crusp (moradia estudantil da USP). No total foram realizadas 20 entrevistas $^{20}$. Os 5 países estão assim representados: Angola, 4; Cabo Verde, 3; Guiné Bissau, 5; Moçambique, 5; São Tomé e Príncipe, 3. Foram contatados representantes de duas associações de estudantes (Angola e Guiné-Bissau) e acessados sites (como o Mozucas ${ }^{21}$, por exemplo).

Os métodos quantitativo e qualitativo - a observação direta e participante fizeram-se presentes durante a pesquisa. De acordo com Hannerz (1980), a observação urbana participante é um modo eficaz de coligir dados. Através da observação participante "é possível chegar a percepções de comportamento que as pessoas não verbalizam com facilidade e os dados que se obtêm podem se centrar melhor nas relações e em seu contexto do que em indivíduos abstratos" (Hannerz, 1980, p. 343). Esses métodos me permitiram escutar, observar e testemunhar o melhor possível o que já havia sido visto e ouvido de meus interlocutores, antes do empreendimento da pesquisa. Através das bibliotecas da USP e da Casa das Áfricas (SP), encomendei, em bibliotecas de dentro e de fora de São Paulo, documentos e folhetos indispensáveis para a análise dos dados, sendo que o estudo teve como base fontes primárias.

A presença de universitários africanos oriundos de países africanos de fala portuguesa em São Paulo, Brasil, foi analisada à luz das transformações - como o contexto de mudanças e reestruturação econômico-social - pelas quais as sociedades africanas têm passado nas últimas décadas e que vêm trazendo um novo diálogo sobre as políticas públicas e educacionais. Uma das questôes que me vem chamando atenção na minha própria experiência e nas conversas tidas com outros estudantes africanos diz respeito aos aspectos que têm motivado pais e familiares a mandarem seus filhos ao Brasil, um país de "desenvolvimento intermediário”, para prosseguirem seus estudos. É necessário perceber a existência de diversas motivações que se escondem por detrás de uma aparente similaridade de projetos e escolhas por parte desses estudantes e de seus familiares. Como bem observou Maria Engrácia Leandro (2004), a elaboração ou reelaboração de projetos migratórios ou de estudos não estaria desligada da dinâmica social e familiar em situações muito concretas, uma vez que normalmente é na família

18. USP e UNESP. Hoje a USP conta com 7I estudantes provenientes dos Palop. Fonte: Comissão de Cooperação Internacional (CCInt) da USP.

19. PUC-SP, Uni-Nove e São Camilo.

20. Dos 20 entrevistados 2 - um cabo-verdiano e uma angolana - não autorizaram a gravação das falas.

21. www.geocities.com/mozucas (página dos estudantes moçambicanos no Brasil). 
e em função dela "que se concebem, tomam forma e realidade e se reelaboram" os projetos de dinâmicas populacionais (Leandro, 2004, p. 95).

\section{Projetos de vida e a escolha do Brasil}

Em termos conceituais, a noção de projeto, assim como da sua objetividade e subjetividade, tem recebido pouca atenção por parte dos sociólogos, como bem reconheceu M. E. Leandro (2004). De acordo com Leandro, foram os filósofos, como J.P. Sartre (1986), M. Merleau-Ponty (1971), E. Husserl, D. Christoss, entre outros, que inicialmente se debruçaram sobre esta problemática.

No Brasil são muitos os autores que atualmente se dedicam ao estudo de projeto. Um dos mais renomados é Gilberto Velho (1994), que vê o mundo moderno como palco da valorização do indivíduo, o que possibilitaria a elaboração de projetos individuais mais do que na sociedade tradicional. $\mathrm{Na}$ sociedade complexa e moderna a família aparece mais como rede de apoio. Myriam Moraes Lins de Barros (1999) diz que o projeto é pensado em condições socioculturais específicas e está ligado aos valores da sociedade. É o aspecto socializado do conhecimento (Schutz, 1974) ou o aspecto público da linguagem (Velho, 1981) que dá ao projeto a possibilidade de existência.

A pesquisa indicou-nos que os projetos destes interlocutores estão mais atrelados à família, embora alguns cheguem a afirmar que suas trajetórias e seus projetos de vida sejam individuais. Para muitos desses estudantes, a família constitui o núcleo central e fonte de equilíbrio.

\section{[...]. Não tem como ser individual porque ele não é individual. \\ Para eu vir para cá é meu irmão que morava comigo que era estudante e trabalhador na época, teve que abrir mão de muita coisa, ele já era pai. E, com certeza, ele pode não ter me dito, mas, com certeza ele abriu mão de muita coisa para me ajudar. Quando eu estava aqui, todos [...] os meus irmãos já eram pais [...], de família e sem muitos recursos. Com certeza eles abriram mão de um monte de coisas para poderem me manter aqui. Então, isso é impagável, não vou pagar nunca. O único jeito de pagar épensar nesse coletivo, mesmo (Fausto-Moçambique).}

É importante frisar que, nas tradiçôes culturais africanas de origem bantu, a idéia de coletividade é muito presente. Para um bantu, "ser" é, fundamentalmente, "estar em relação com os outros" (Tempels, 1965, p. 38). Com isso não quero afirmar que em países de economia de mercado, como é o caso dos Palop, não se faça presente o "individualismo". Ele existe, mas os resquícios das sociedades simples, que por sua coalizão deram origem às soberanias atuais, aca- 
bam prevalecendo nas famílias, sejam elas nucleares ou alargadas. Como diria Elísio Macamo (2008), em África "todos [vivem] num contexto social moderno, mas na base de referências sociais tradicionais. É um contexto extremamente individualista, mas a [...] resposta a essa condição é a família e a comunidade" (p. 67). Hoje, quando o diploma universitário vem se tornando o principal passaporte de construção do futuro das jovens gerações, as famílias vêem-se na obrigação de mobilizar-se para ter um doutor no seio da família, o que lhes permitirá aceder ou não a outra posição social. "É sempre bom ser uma referência na família. É muito gratificante [...]” (Sonia - Guiné Bissau).

Eu acho que éo orgulho de ter amanhã alguém com nivel universitário. Eu não acredito [...] que nenhum deles esteja à espera da minha ajuda para melhorar alguma coisa na vida deles. Não acredito, tenho certeza disso. Mas eles [... estão à espera de algum dia dizer para os amigos deles que têm um irmão que se formou, na universidade X, fora de Moçambique. Jáé um privilegio para eles, éum privilegio para mim também (Fausto - Moçambique).

Ao escolher um país para prosseguir os estudos, o Brasil acaba apresentando vantagens por causa dos laços de amizade que unem o Brasil com os Palop, com ênfase em suas especificidades históricas, sociais, econômicas, educacionais e culturais. A língua portuguesa, que é oficial no Brasil e nos Palop, acaba sendo um dos atrativos para esses estudantes.

O Brasil foi minha primeira opção por causa da lingua portuguesa, que éum facilitador. Já pensei em estudar em Portugal mais pela lingua também. Acabei escolhendo o Brasil porque sabia que era um pais lider em cursos de jornalismo e comunicação (VandaCabo Verde).

Vale notar que, em termos de custos, sai mais barato mandar um filho para prosseguir seus estudos no Brasil do que na África do Sul, na Austrália, nos EUA, na Inglaterra e em Portugal, por exemplo. O custo de vida do Brasil seria mais baixo que dos países citados. A oportunidade também é apontada como um dos fatores que traz esses estudantes ao Brasil.

Eu fui para África do Sul, mas não gostei. Voltei para Angola, estava à espera de uma bolsa para o Canadá, depois as coisas começaram a correr mal. Não tive alternativa a não ser o Brasil (Jorge-Angola).

Na verdade, não foi uma escolha. Em Moçambique a dificuldade de fazer curso superior é muito grande. [Depois] que consegui terminar o ensino secundário, não consegui entrar no ensino superior lá, entrei numa escola técnica de jornalismo em Moçambique (Fausto - Moçambique). 
Muitos são os que escolhem fazer um curso no Brasil sem ter nem sequer uma idéia do que seja esse curso. Outros escolhem o Brasil por influência de amigos ou parentes que aqui moram ou moraram. Uns chegaram a imaginar que o Brasil fosse um "paraíso social", sinônimo de desenvolvimento e progresso; portanto, de uma vida farta e de oportunidades incomensuráveis para todos. Muitos chegam a imaginar que o estilo de vida e o Brasil mostrado nas telenovelas da Rede Globo de Televisão e da Rede Record Internacional seria o Brasil real, ou seja, o Brasil que eles haveriam de encontrar. $\mathrm{O}$ que mostram os meios de comunicação "é uma perfeição" (Sonia - Guiné Bissau). O que "eles mostram na novela é uma coisa totalmente diferente. Tipo Rio de Janeiro, praias, Copacabana [...]. É a única noção que eu tinha" (Carla - São Tomé e Príncipe).

Esses estudantes não partem numa situação de total desconhecimento acerca da nova realidade social que os receberá. De fato, há toda uma vasta rede de relaçôes que se vai tecendo e reatualizando entre os primeiros que partem e os que ficam, o que faz com que estes possam elaborar certa constelação de elementos avaliativos em relação à sua provável situação futura. Contudo, agora que conhecem o Brasil, muitos dos meus interlocutores voltariam para cá para prosseguir com seus estudos, porque o ambiente de estudos encontrado é considerado bom. Cá os professores são "muito legais" e "dispostos a ajudar". Muitos são os que afirmam que a experiência é mais "gratificante" do que dolorosa e o ambiente universitário do Brasil incentiva o crescimento científico.

\section{Sociabilidade e redes sociais}

As redes sociais não são um dado natural; antes, são construídas através de estratégias de investimento nas relações sociais, passíveis de serem utilizadas como fontes de benefícios (Bourdieu, 1980). A análise de redes não seria apenas um instrumento de investigação urbana. Ela "começou a ganhar importância graças ao interesse antropológico pelas sociedades complexas (Hannerz, 1980, p. 188).

Uma rede social pode ser definida como "um conjunto de unidades sociais e de relações, diretas ou indiretas, entre essas unidades sociais, através de cadeias de dimensão variável" (Mércklé, 2004, p.4). As unidades sociais podem ser indivíduos ou grupos de indivíduos, informais ou formais, como associações, empresas, países. As relações entre os elementos da rede podem ser transações monetárias, troca de bens e serviços, transmissão de informações; podem envolver interações face a face ou não; podem ser permanentes ou episódicas. Do ponto de vista metodológico, a abordagem a partir da teoria das redes permite usufruir de um conjunto de dispositivos solidamente estruturados e testados. A linguagem, os conceitos, os indicadores, os métodos de recolha e tratamento 
de dados da network analysis constituem um corpo analítico que oferece inúmeras possibilidades heurísticas e grande flexibilidade temática (Knoke; Kuklinski, 1982, p.13).

Neste trabalho, a questão da sociabilidade e das redes sociais, assim como o seu significado, recebeu uma atenção especial. Partindo de entrevistas, procurei desvendar como os estudantes oriundos dos Palop formam suas redes de relações, identificando como essas redes se organizam, suas estratégias, desde os países da emigração - no momento do afastamento do ambiente familiar até o país de imigração (Brasil). Em termos de residência, há uma maior concentração dessa população em alojamentos da Universidade de São Paulo (USP). Outros moram em repúblicas, em casas de famílias e em apartamentos alugados. A escolha do lugar de moradia, muitas vezes, está condicionada à proximidade da universidade, à facilidade de transporte, ao valor do aluguel e à segurança. Poucos moram sozinhos. Muitos moram com outros estudantes e/ou indivíduos. De acordo com os meus interlocutores, existe uma diferença entre morar com compatriotas e com pessoas de outras nacionalidades. Entre estudantes oriundos do mesmo país existiria uma compatibilidade nos hábitos. Mesmo assim, nem todos vêem a experiência de morar com pessoas de outras nacionalidades como uma experiência negativa, pois há uma troca de elementos culturais.
[...]. A menina que mora aqui é brasileira. Nós nos damos super bem. Ela tem pele branca, mas ela se identifica muito com as ori- gens africanas, e se sente um pouco africana Ela usa tranças e quer aprender o crioulo de São Tomé. Eu me sinto familiarizada com ela como com o colega que é do meu país também (Talita-São Tomé e Príncipe).
Moro com dois brasileiros. É diferente de morar com pessoas do seu pais. Com pessoas do seu país você fala a sua língua, está mais em casa. Vocêtem mais vontade, por exemplo, de fazer uma comidinha do seu país toda a semana. Mas se você está morando compessoas de outro país, você faz a comida, mas nem sabe se eles gostam. Você coloca uma música de Cabo Verde, mas eles nem prestam atenção. Quando passa uma notícia sobre Cabo Verde eles nem se interessam. O lado bom de morar com pessoas de outras nacionalidades é apren- der sobre a cultura do outro, aprender sobre o outro, opais do outro (Maura-Cabo Verde).

De uma maneira geral, esses estudantes, quando procuram suas parceiras ou seus parceiros para ficar ${ }^{22}$, namorar ou casar não dão muita importância aos

22. Ficar: Namorar sem compromisso, durante um curto espaço de tempo, às vezes por uma noite. Cf. Ferreira, Aurélio B. Holanda. Novo dicionário da língua portuguesa, 2000. 
fatores raça, religião ou origem socioeconômica, e sim à "compatibilidade". Os namoros são mais comuns entre os homens com as brasileiras. Preferem as brasileiras. As principais motivações por mim identificadas entre os meus interlocutores seriam a receptividade, a simpatia e a beleza da mulher brasileira.

É engraçado que se vou numa festa dos Palop, se estiverem lá brasileiros, tenho muito mais facilidade de conversar com uma menina brasileira do que com uma menina dos Palop. A gente é muito conservadora. O tempo que você leva para ganhar uma confiança [...] de uma menina africana [...], e o tempo que você leva para ganhar confiança de uma menina brasileira na mesma festa é absolutamente diferenciado. Se [as africanas] ficam naquela reticência ainda, se nega ou vai, você vai numa brasileira. Ela ésuper aberta para conversar [...] (Ivan - Angola).

Entre os meus interlocutores, os cabo-verdianos são os que mais namoram entre si.

Eu acho que os cabo-verdianos namoram mais com gente de Cabo Verde. Não seipor que convivem mais do que com pessoas de outros países. Você acha aqueles que namoram com brasileiros, guineenses, angolanos, mas eu acho que fica tudo em casa. A relação acontece. Já namorei com cabo-verdiano e brasileiro, mas eu prefiro namorar com cabo-verdiano. Os brasileiros não levam a relação a sério, os guineenses e os angolanos também. Os moçambicanos eu não sei (Vanda-Cabo Verde).

As mulheres evitam envolver-se com homens brasileiros por achar que "os homens brasileiros não levam a relação a sério" (Vanda). Mas também há aquelas que não descartam a possibilidade de namorar brasileiros. Em meados de 2007, por exemplo, uma guineense contraiu matrimônio com um brasileiro (gaúcho). Situação semelhante foi observada em pesquisas similares (Subuhana, 2005; Belhadj, 2000). Marnia Belhadj (2000), em seu estudo sobre as filhas de pais magrebinos, ${ }^{23}$ descobriu que as escolhas matrimoniais, basicamente para o caso das mulheres, não passavam de um ajuste entre aspirações pessoais e expectativas familiares. Isso se daria porque haveria uma vontade de preservar os laços familiares e de manter a coesão da família. Lá, a escolha do cônjuge resultaria, segundo a autora, de um ajuste entre suas próprias aspiraçóes e as experiências familiares. Se de um lado a tal escolha era percebida como estritamente pessoal, do outro "ela é ainda tributária de certas condições impostas pelos pais, como o fato de que o futuro cônjuge deve pertencer à população

23. Na França, os países do norte da África (Argélia, Tunísia e Marrocos) são denominados de Maghreb. Daí o adjetivo maghrébin, em português magrebino. 
muçulmana e magrebina". ${ }^{24}$ Contudo, a autora reconhece que hoje, mesmo nas sociedades modernas, a escolha do cônjuge continua a obedecer, de maneira consciente ou inconsciente, a certos tipos de determinismos sociais, culturais e religiosos que contribuem para reduzir a liberdade individual. Tais normas, segundo M. Berlhadj, obrigaria essas jovens, com freqüência, a desenvolverem estratégias visando a conciliar as próprias aspiraçóes com as de sua família (M. Berlhadj, 2000, p. 68).

\section{As festas}

Falar de festas é falar de identidade. Elas nos revelam com quem essa população anda e nos mostram como é que essa geração preserva as tradições dos países de origem. Como referiu Elísio Macamo (1998), as nações africanas são tanto tradicionais quanto modernas. Nessas festas é na comida, nos pratos típicos, como mukapata (Moçambique), cachupa (Cabo Verde), por exemplo, que essa geração deixa transparecer a preservação das tradições africanas: " $n a$ roupa e na música não tanto". Como disse um dos meus entrevistados, "o que identifica mais o moçambicano é a comida" (Fausto - Moçambique).

Os moçambicanos que eu conheço, pelo menos a maioria deles, são muito de hip-hop, rap, e aquelas baladas só de estilo do negro norte-americano. O que identifica mais o moçambicano é a comida. Se eu sair para ir curtir um samba com um amigo e tal, não sei o que, eu vou gostar, mas se o Euclides, que é moçambicano, me chamar e disser, "vem aqui na minha casa, a gente está comendo um carril de amendoim", vai ser uma sensação muito diferente. Vai ser boa, do mesmo jeito, mas a sensação, eu acho que o que mais me identifica como moçambicano está no convivio com o moçambicano. Acho que está no convívio em que predomine a cultura moçambicana (Nerito-Moçambique).

O que identifica mais o cabo-verdiano e o guineense é o crioulo.

O que identifica mais o cabo-verdiano é o crioulo, tal como os guineenses. Porque música, você escuta várias músicas, mas o crioulo não tem igual. Até a comida você acha alguma coisa parecida aqui, mas o crioulo é o crioulo. Por exemplo, se vocêpassa muito tempo com brasileiro e depois encontra um crioulo você começa a falar em português com a pessoa, e depois os dois vão se entrosando, mas depois [...], é maravilhoso (Vanda - Cabo Verde).

24. Segundo a autora, o casamento dos homens muçulmanos com uma mulher não-muçulmana é, em geral, mais aceito e mais bem tolerado, na medida em que ele não acarreta as mesmas conseqüências e que se considera que os homens têm maior poder que as mulheres no sentido de propiciar a conversão do outro cônjuge. 
As festas organizadas anualmente para a comemoração da independência de seus países de origem, para além de serem "momentos de descontração", servem também para reunir essa população. Nelas, o estar perante os compatriotas e amigos não deixa de ser uma forma de superar a saudade.

Eu convivo bem com outros Palop. Quando a gente se encontra nas festas, a gente lá aprende o semba, eles têm uma paciência para ensinar, né? É muito legal. Você se sente com os seus irmãos. Por exemplo, a gente está a qui, não tinha a minha conterrânea, era só eu, e sempre que tinha alguma coisa corria para eles me ajudarem, a gente conversa. Eu me sinto mais em casa estando com os Palop (Vanda-Cabo Verde).

Nessas festas, esses estudantes também reconstroem suas memórias individuais, que se conjugam com a memória oficial - daí a presença das bandeiras e dos hinos nacionais. As lembranças não se limitam às suas trajetórias individuais nem à vida familiar; seus relatos falam de acontecimentos políticos e sociais. São Associações de Estudantes (Angola, Cabo Verde e Guiné Bissau) que organizam os eventos para a celebração de datas festivas. Para além de serem agentes de difusão de informações, são os membros dessas Associaçôes que acolhem os recém-chegados.

O desenrolar da pesquisa me fez crer que não só existe uma circularidade nos projetos desses estudantes, como também se manifesta a vontade de preservar a herança cultural, através da manutenção de hábitos culinários e estéticos. Do mesmo modo, esses encontros operam as celebrações de festas em comemoração à independência de seus países de origem, assim como permitem uma identificação com compatriotas, com outros africanos, com os Palops, com os pertencentes à Comunidade dos Países de Língua Portuguesa (CPLP) e com os de outras nacionalidades e comunidades regionais ou transfronteiriças.

Não é diferente com as chamadas redes virtuais. Além dos contatos face a face, há interaçōes em redes virtuais, tais como o Mozucas ${ }^{25}-$ site $^{26}$ e comunidade $^{27}$-, que foi criado em 2001 com o princípio de encurtar as distâncias entre os estudantes e residentes moçambicanos no Brasil. Tem como principal objetivo facilitar o convívio e a troca de idéias entre eles, sem nemhum tipo de formalidades. O caso exemplar do Mozucas revela como os moçambicanos que estudam no Brasil têm suas redes de relaçôes com outros moçambicanos que também aqui moram, com os amigos em Moçambique, com os amigos brasileiros e demais contatos em outros cantos do mundo. Outras redes virtuais

25. MOZUCAS $=$ Mozes + brazucas

26. www.geocities.com/mozucas

27. http://groups.yahoo.com/group/mozucas 
existem entre cabo-verdianos, angolanos e outros. O que importa é que esses estudantes formam uma círculo de relações ampliada, a qual acolhe também indivíduos de outras nacionalidades, possibilitando não apenas a vivência de contatos face a face como também a interação através de redes virtuais.

\section{Atitudes de preconceito e discriminação}

O "preconceito de cor" e/ou "preconceito racial" é apontado como a principal causa do mal-estar de um número considerável desses estrangeiros, mus interlocutores, em terras brasileiras. Há que reconhecer que os brancos, alguns mestiços e poucos negros afirmam que não se sentem discriminados por causa do "tom de pele".

Vale notar que, mesmo entre os negros, há aqueles que afirmam ter mais facilidade de detectar que estão sendo discriminados em relação aos outros. Talvez sejam vítimas de "discriminação sofisticada" (Santos, 2002, p.36). Segundo Hélio Santos, muitas das vezes, quando a pessoa está sendo vítima de "discriminação sofisticada", raramente consegue se aperceber. Esse tipo de discriminação, difícil de captar, seria o mesmo que sofre a classe média negra brasileira. O que notei em quase todas as entrevistas é o reconhecimento de que o fato de ser universitário e estrangeiro atenua a experiência negativa que representa descobrir-se em desvantagem social pela simples pigmentação da pele. Todavia, muitos são os que dizem ter passado por situaçôes constrangedoras pelo fato de terem uma tonalidade de pele escura, por serem negros. São vários os ambientes sociais - como prédios residenciais, ônibus, supermercados, restaurantes, em festas, dentro da universidade, entre outros - que obrigam esses estudantes a refletir sobre a sua condição de "preto".

Especificamente diria que [foi] num restaurante. Na época namorava uma menina branca. A gente entrou para comer num restaurante, e a única possibilidade que o garçom achou, "o cara ali entrar naquele restaurante, era negro que tinha que ser estrangeiro". Ele já veio me atender falando inglês. Ai olhei para ele e disse: "mas eu falo português, podes falar português comigo". Levou aquele baita susto e eu falei para ele: "eu entendo". [...] Era um garçom negro. Com a mesma menina passei por uma outra situação. Era bem tarde da noite, a gente estava caminhando à procura de algum táxi, a gente foi parado por policiais, e com arma mesmo, eles nos apontaram com a arma, "mãos para o ar". A gente ficou naquele pânico e tudo, fomos revistados, apontaram arma na nossa cara, pediram documentos [...]. Mas ai, nos documentos tinha a carteirinha da USP. Na hora que ele viu a carteirinha pensou "é universitário, [...] universitário da USP" $e$ [disse], "podem ir". Eu 
falei que "não, você nos apontou arma, fez o maior estralhaço aqui e não vai explicar por quêe?". Ele falou para mim, "você já tem a sorte de estar vivo. Então, toma cuidado. Você não está em condiçôes de me fazer pergunta nenhuma". Automaticamente fiquei com medo. É a sua vida que está em jogo! É revoltante, é muito revoltante (Fausto - Moçambique).

\section{A expectativa do retorno}

Para além do compromisso diplomático assumido, que é de "retornar a seu país de origem em período não superior a três meses" (Protocolo, seção X, Cláusula 23) após o término dos estudos, quase todos manifestam o interesse de regressar para contribuir para o progresso de seu país, trabalhando ou dando aulas, e formar família.

Eis o comentário de um dos entrevistados: "Terminando os meus estudos eu vou direto para Angola. Sou uma pessoa bem família, quero ficar com os meus familiares. Se for para fazer sucesso faço lá mesmo" (Jorge - Angola).

Os meus interlocutores imaginam poder dar o máximo de si e esperam ter um "enquadramento" que lhes facilite "transmitir" os conhecimentos adquiridos no Brasil. Mas há aqueles que reconhecem que nem tudo será maravilhoso e têm suas reservas, pois hoje em dia o mercado dos Palop, bem como os de outros países em África, tornou-se muito competitivo. De uma maneira geral, esperam aplicar os conhecimentos adquiridos no Brasil nas realidades de seus países, dando aulas, envolvendo-se em organismos governamentais e não-governamentais ou criando seus próprios negócios.

Eu estou pensando em fazer uma pós-graduação. Na verdade, eu queria terminar e voltar no dia seguinte, mas, na verdade, agora que o curso está para terminar fica aquele aperto: "Como é que vai ser lá. Eo trabalho, será que vou conseguir? Será que se eu consigo uma pós-graduação aqui, será que eu faço? Será que eu consigo uma bolsa?" Não tem como falar "eu vou voltar de imediato"(VandaCabo Verde).

Os projetos de vida de muitos desses estudantes, plenos de incertezas e de lutas, estão atrelados à família, embora alguns cheguem a afirmar que suas trajetórias e seus projetos de vida sejam individuais. Existe uma circularidade e uma dimensão cultural nesses projetos, e a família é central em muitas culturas africanas. Nesse sentido, a busca por qualificação fora do lugar de origem exige muitos sacrifícios. A tia de uma das entrevistadas, por exemplo, penhorou uma casa para que a sobrinha pudesse conseguir a vaga. 
As telenovelas - um dos principais artigos de exportação do Brasil - estão entre os fatores que contribuem para que esta população queira cruzar o Atlântico para fazer estudos de graduação e pós-graduação no Brasil. Dificuldades naturais de adaptação e a questão financeira estão entre as dificuldades mais citadas. Alguns vêm de famílias que pertencem às elites econômicas ou políticas de seus países, enquanto outros não têm recursos e dependem de bolsas. Como são estudantes, não podem ter emprego, apenas estágios - nem sempre fáceis de obter. Por sua vez, o retorno também não garante uma inserção profissional imediata e nos moldes desejados; assim, prolongam-se os estudos na expectativa de conseguir um futuro melhor.

Muitas das vezes, a imagem veiculada na mídia brasileira sobre o continente africano e os africanos é negativa, e isso faz com que muitas pessoas achem que África é um país só: um país de atraso e de guerras, mas não de realidades em reconstrução após tantas lutas intestinas e em busca de um lugar na composição do mundo moderno.

A facilidade com a língua falada no Brasil, o custo de vida baixo em comparação com outros países, a valorização da formação universitária no Brasil e a integração e a amizade com os brasileiros constituem fatores positivos para aqui estar e, em muitos casos, constituir família, por vezes, com brasileiros. Como poucos têm recursos para visitar a família nas férias, a saudade é driblada com e-mails, cartas, telefonemas e "torpedos" via celular. Contudo, permanece a pergunta quanto a ficar no país de acolhimento, por tudo que foi vivido e pelo muito que ainda se busca, ou retornar, voltar para o país de origem e exercitar aí o muito que se aprendeu. No Brasil ou na terra natal as incertezas permanecem a desafiar projetos pessoais e coletivos, a desafiar identidades transformadas pela trajetória e a indagar pelos compromissos políticos, sociais e familiares com um lugar cada vez mais distante.

\section{Conclusão}

No presente trabalho, faço uma breve consideração sobre a minha história de vida e a particular experiência de outros africanos dos Palop que migraram para o Brasil em busca de formação e qualificação de nível superior, em particular na cidade de São Paulo.

$\mathrm{O}$ viver fora do país de origem parece reavivar a necessidade de não perder as tradiçôes culturais de origem e de pertença, ao mesmo tempo que cada estudante se transforma em um ser globalizado e parte de um mundo moderno. Como afirmei em outro trabalho:

os moçambicanos, duma maneira geral, e os meus parentes, em particular, sabiamente conseguiram incorporar em seu vocabu- 
lário a idéia de nação, sem com isso significar o abandono das tradiçôes culturais locais, adquiridas de seus antepassados. (Subuhana, 2006, p. 14). ${ }^{28}$

Tal processo não foi muito diferente em outros países de língua portuguesa após sua independência. $\mathrm{O}$ fato suscitou, por parte dos jovens, a busca por mais educação que os fizesse "civilizados", apartando-os daqueles que não tinham o mesmo destino ou possibilidade. Muitos desses jovens migravam para a cidade onde almejavam encontrar um modo de vida que se adequasse à instrução adquirida. De entre eles, resulta o contingente que migra em busca de formação superior longe de seu lugar de origem, dando continuidade a um processo de migração por etapas - do mundo rural a cidades interioranas, depois para as capitais e, finalmente, por diferentes caminhos, a um país estrangeiro, como África do Sul, Brasil, França, Portugal, entre outros.

Os estudantes africanos permanecem muitos anos fora de seu lugar, alguns retornam nas férias, por curtos períodos para repor seus laços, rever amigos e parentes, mas quase nunca permanecem no país onde nasceram. Não se sabe exatamente quantos retornam, o que se sabe é que muitos consolidam suas vidas nos lugares aos quais um dia foram para estudar e voltar e, então, não voltam. O dilema é pensar a reconstrução dos países de língua portuguesa na busca por fazer deles naçôes modernas que possam, assim, ocupar um lugar no mundo e resolver as dificuldades desse processo em termos de acolher os quadros de formados que possam retornar.

A questão é se é possível imaginar as novas nações africanas - Moçambique, Angola, Cabo-Verde, Guiné Bissau ou São Tomé e Príncipe - como projeção do presente para o futuro, sem que para isso seja necessário abandonar as tradiçôes culturais locais ou abraçar de modo incondicional a cultura ocidental. Sem que estudar, globalizar-se, ser moderno possa significar a perda das raízes, um caminho sem volta. Migrar com finalidade de estudo em busca da transformação pessoal e familiar é processo do qual não se tem a medida e o domínio. É processo que coloca em movimento a condição de identidade, autonomia e cidadania diante do sujeito como ser individual, coletivo e político.

28. "A política de assimilação do poder colonial, que objetivava criar no [nativo] uma mentalidade Iusitana, seguiu, com a Frelimo, uma ótica coerente com seus princípios, através do 'homem novo', do proletariado, de uma nova visão de educação, tendo a língua portuguesa como a base da unidade nacional" (Colaço, 200 I, p. 92). 


\section{Referências bibliográficas}

BELHADJ, M. Mulheres francesas de origem argelina. Conquista da autonomia e reelaboração dos modelos familiares tradicionais. In: PEIXOTO, C. E.; SINGLY, François de; CICCHELLI, V. (Org.). Família e individualismo. Rio de Janeiro: Editora FGV, 2000. p. 63-78.

BORGES, E. A política cultural em Moçambique após a Independência (1975-1982). In: FRY, P. (Org.). Moçambique: ensaios. Rio de Janeiro: Editora UFRJ, 2001. p. 225-247.

BOURDIEU, P. Lessense pratique. Paris: Minuit, 1980.

COLAÇO, J. C. Trabalho como política em Moçambique: do período colonial ao regime socialista. In: FRY, Peter (Org.). Moçambique: ensaios. Rio de Janeiro: Editora UFRJ, 2001. p. 91-108.

DESIDÉRIO, E. J. Migração internacional com fins de estudos: o caso dos africanos do Programa Estudante-Convênio de Graduação em três universidades públicas no Rio de Janeiro. 2006. Dissertação (Mestrado) - Escola Nacional de Ciências Estatísticas, Instituto Brasileiro de Geografia e Estatística, Rio de Janeiro.

ELIAS, N.; SCOTSON, J. Os estabelecidos e os outsiders: sociologia das relações de poder a partir de uma pequena comunidade. Rio de Janeiro: Zahar, 2000. 224 p.

FRY, P. (Org.). Moçambique: ensaios. Rio de Janeiro: Editora UFRJ, 2001.340 p.

HANNERZ, U. Exploring the city: toward an urban anthropology. New York: Columbia University Press, 1980.

KNOKE, D.; KUKLINSKI, J. H. Network analysis. London: Sag, 1982.

LEANDRO, M. E. Dinâmica social e familiar dos projetos migratórios: uma perspectiva em análise. Análise Social — Revista do Instituto de Ciências Sociais da Universidade de Lisboa, v. 39, n. 170, p. 95-118, abril e junho de 2004.

LINS DE BARROS, M. M. A cidade dos velhos. In: VELHO, G (Org.). Antropologia urbana: cultura e sociedade no Brasil e em Portugal. Rio de Janeiro: Zahar, 1999. p. 43-57.

MACAMO, E. A influência da religião na formação das identidades sociais no sul de Moçambique. In: SERRA, C. Identidade, moçambicanidade, moçambicanização. Maputo: Livraria Universitária (UEM), 1998. p.35-60.

MACAMO, E. Planície sem fim. Maputo: Ndjira, 2008. 150 p.

MACHEL, S. A luta contra o subdesenvolvimento. Maputo: Edição do Partido Frelimo, 1983. (Coleção “Textos e Documentos”, n. 4).

MERCKLÉ, P. Sociologie des reseaux sociaux. Paris: La Découverte, 2004.

MONDLANE, E. Lutar por Moçambique. Lisboa: Sá da Costa, 1975.251 p.

MUUS, P. La migration internationale dans et vers la Région Économique Europénne (REE). Tendances passées et prévisions pour la future migration internationale. In: COLLOQUE ÉUROPÉEN LA SÉCURITÉ SOCIALE EN EUROPE ÉGALITÉ ENTRE 
NATIONAUXET NON NATIONAUX, 10-12 nov. 1994, Porto. Actes... Lisboa: DRICSS, 1995. p. 159-189.

PETRUS, M. R. Emigrar de Angola e imigrar no Brasil: jovens imigrantes angolanos no Rio de Janeiro: histórias(s), trajetórias e redes sociais. 2001. Dissertação (Mestrado) - Instituto de Pesquisa e Planejamento Urbano e Regional, Universidade Federal do Rio de Janeiro, Rio de Janeiro, 2001.

ROCHA-TRINDADE, M. B. Sociologia das migraçôes. Lisboa: Universidade Aberta, 1995. $410 \mathrm{p}$.

SANTOS, H. Negro não é problema, é solução [entrevista]. Caros Amigos, ano 6, n. 69. São Paulo: Casa Amarela, 2002. p. 31-37.

SAYAD, A. A imigração ou os paradoxos da alteridade. São Paulo: EDUSP, 1998.

SCHUTZ, A. Estudios sobre teoría social. Buenos Aires: Amarrortu, 1974.

SUBUHANA, C. Estudar no Brasil: imigração temporária de estudantes moçambicanos do Rio de Janeiro. 2005. 210 p. Tese (Doutorado em Serviço Social) - Escola de Serviço Social, Universidade Federal do Rio de Janeiro, Rio de Janeiro, 2005.

SUBUHANA, C. Minha histórialtrajetória de vida inserida na problemática da construção da cidadania e da nação moçambicana. São Paulo: Casa das Áfricas, 2006. Disponível em: <http:/ /www.casadasafricas.org.br/site/img/upload/749450.pdf.>. Acesso em: 12 jul. 2008.

TEMPELS, P. La philosophie bantoue. Paris: Présence Africaine, 1965.

VELHO, G. Projetos e metamorfose: antropologia das sociedades complexas. Rio de Janeiro: Zahar, 1994.

VELHO, G. "Projeto, emoção e orientação em sociedades complexas". In: VELHO, G. Individualismo e Cultura. Notas para uma antropologia da sociedade contemporânea. Rio de Janeiro. Zahar, 1981. p. 121-132.

Recebido em 15 de julho de 2008 e aprovado em 26 de setembro de 2008.

Pro-Posições, Campinas, v. 20, n. 1 (58), p. 103-126, jan./abr. 2009 